\title{
FasL on decidual macrophages mediates trophoblast apoptosis: A potential cause of recurrent miscarriage
}

\author{
JINLI DING $^{1 *}$, TAILANG YIN ${ }^{1 *}$, NANA YAN ${ }^{2}$, YANXIANG CHENG ${ }^{3}$ and JING YANG ${ }^{1}$ \\ ${ }^{1}$ Reproductive Medical Center, Renmin Hospital of Wuhan University and Hubei Clinic Research Center for \\ Assisted Reproductive Technology and Embryonic Development, Wuhan, Hubei 430060; \\ ${ }^{2}$ Yichang Central People's Hospital, Yichang, Hubei 443000; ${ }^{3}$ Department of Gynecology and Obstetrics, \\ Renmin Hospital of Wuhan University, Wuhan, Hubei 430060, P.R. China
}

Received November 1, 2018; Accepted March 21, 2019

DOI: 10.3892/ijmm.2019.4146

\begin{abstract}
Macrophages can induce Fas ligand (FasL)-mediated apoptosis, and the deregulation of apoptosis is known to be associated with recurrent miscarriage (RM). The aim of the present study was to investigate the possible involvement of FasL in macrophage-mediated trophoblast apoptosis and its potential role in RM. Human decidual and placental villous tissues were collected from 81 women (21 for the RM group, 26 for the spontaneous abortion group and 34 for the control group) at 7-9 weeks of gestation. The distribution changes of macrophages and the expression of FasL on macrophages were evaluated by immunohistochemical, immunofluorescence and western blot analyses. A macrophage and trophoblast co-culture model was used to determine the effects of FasL on the apoptosis of trophoblasts. The results indicated that CD86 ${ }^{+}$ macrophage populations in decidual tissues were significantly increased, accompanied by reduced $\mathrm{CD} 163^{+}$macrophages in the abortion and RM groups. Furthermore, the distribution of $\mathrm{CD} 68^{+}$macrophages was also significantly altered in
\end{abstract}

Correspondence to: Professor Yanxiang Cheng, Department of Gynecology and Obstetrics, Renmin Hospital of Wuhan University, 238 Jiefang Road, Wuhan, Hubei 430060, P.R. China

E-mail: chengyanxiang6435@163.com

Professor Jing Yang, Reproductive Medical Center, Renmin Hospital of Wuhan University and Hubei Clinic Research Center for Assisted Reproductive Technology and Embryonic Development, 238 Jiefang Road, Wuhan, Hubei 430060, P.R. China

E-mail: 13507182023@163.com

${ }^{*}$ Contributed equally

Abbreviations: RM, recurrent miscarriage; FasL, Fas ligand; PMA, phorbol 12-myristate 13-acetate; $\mathrm{dM} \Phi$, decidual macrophage; BMI, body mass index; FBS, fetal bovine serum; DAPI, 4',6-diamidino-2-phenylindole

Key words: recurrent miscarriage, Fas ligand, macrophage, trophoblast, apoptosis specimens from the abortion and RM groups, and they were observed to have infiltrated into the trophoblast cells. In addition, elevated expression of FasL on $\mathrm{CD}^{+} 8^{+}$and $\mathrm{CD} 86^{+}$ macrophages in the decidua was observed in the spontaneous abortion and RM groups of patients, and FasL was demonstrated to mediate the induction of trophoblast apoptosis by macrophages in co-culture. These results indicate that the aberration of macrophage-induced FasL-mediated apoptosis may represent one of the causes of RM.

\section{Introduction}

Recurrent miscarriage (RM) is a common reproductive complication, which affects $1-3 \%$ of women during their reproductive years (1). Recent studies on the pathological factors of RM have made substantial progress and immunological factors have drawn the attention of researchers. Numerous studies have reported associations between immune cells and RM, among which the role of macrophages has been confirmed. Macrophages account for $20-25 \%$ of all decidual leukocytes at the site of implantation, serving vital roles in regulating the maternal immune microenvironment by linking the adaptive and innate immune systems (2). It has already been confirmed that aberrant macrophage infiltration at the maternal-fetal interface is associated with RM (3-5). Macrophages may be polarized into the M1/M2 subtype in specific environments; M1 macrophages produce pro-inflammatory cytokines and regulate inflammatory responses, whereas M2 macrophages promote tissue remodeling and repair (6). Early reports have indicated that decidual macrophages ( $\mathrm{dM} \Phi)$ may be polarized into the M2 subtype in normal pregnancy (7), whereas those in pregnancy complications, including RM or preeclampsia, polarize into the M1 subtype and mediate inflammatory responses $(4,8)$.

Apoptosis is important for normal development of the placenta and, in a normal pregnancy, apoptosis is observed in the trophoblast layer of the placenta (9). Several studies have reported an association between the deregulation of apoptosis and RM (10,11). The Fas/Fas ligand (FasL) system resembles one of the major apoptotic pathways in tissues and cells. The expression of FasL has been identified in several types of immune cell, including activated $\mathrm{CD} 8^{+}$cells, $\mathrm{CD} 4^{+}$ 
T-helper type 1 cells, natural killer cells and monocytes (12). A previous study suggested that Fas/FasL-mediated cell death was associated with cyclic changes in the bovine endometrium (13). Furthermore, excess macrophages in the preeclamptic decidua may induce trophoblast apoptosis (14), and patients with RM have been reported to have elevated expression of FasL (15-17). In addition, FasL can function as a cytokine to induce apoptosis in susceptible cells in vitro (18), and macrophages have been reported to induce FasL-mediated apoptosis in a model of pulmonary silicosis (19) and in chronic demyelinated neuropathy (20). Although higher incidences of trophoblast apoptosis and macrophage infiltration have been detected in the decidua and placental villous tissues from pregnancies in women with RM $(3-5,10,11)$, the effect of macrophages on trophoblast apoptosis, the involvement of FasL in this process, and its potential role in the pathophysiology of $\mathrm{RM}$ remain to be fully elucidated.

In the present study, the distribution pattern of macrophages and the expression of FasL on macrophages were assessed in clinical decidua samples. Furthermore, the role of FasL in the process of macrophage-mediated trophoblast apoptosis was examined in a macrophage and trophoblast co-culture model. The results indicated that $\mathrm{CD} 86^{+}$macrophage populations in decidual tissues were significantly increased, accompanied by the reduced expression of $\mathrm{CD} 63^{+}$macrophages in $\mathrm{RM}$ and spontaneous abortion groups of patients. Furthermore, the distribution of $\mathrm{CD}^{+} 8^{+}$macrophages was significantly altered in RM, with infiltration into the trophoblast cells. In addition, the elevated expression of FasL on $\mathrm{CD}^{+} 8^{+}$and $\mathrm{CD}^{+} 6^{+}$ macrophages was observed in the decidua of RM and spontaneous abortion groups of patients, and FasL was reported to affect trophoblast apoptosis mediated by co-culture with macrophages. These results indicate that the aberration of macrophage-induced FasL-mediated apoptosis may represent one of the causes of spontaneous abortion, even for RM, suggesting that the unfortunate pregnancy outcomes of these two groups may partly result from the same causes.

\section{Patients and methods}

Patients and tissue samples. Women attending the Reproductive Center of Renmin Hospital of Wuhan University (Wuhan, China) were enrolled in the present study between January 2016 and January 2019. A total of 81 patients at between 7-9 weeks of gestation were enrolled, including $21 \mathrm{RM}$ patients (RM group), 34 women undergoing electively induced abortion of a pregnancy (control group) and 26 women who underwent spontaneous abortion (abortion group). The inclusion criteria were an age of $<35$ years, a normal body mass index (BMI) and a regular menstrual cycle. Women with any endometrial or uterine pathology, endometriosis genetic abnormalities or anovulation were excluded. RM was defined as clinically spontaneous abortion occurring prior to 20 weeks of gestation on at least two occasions. Decidual and placental villous tissues were washed in PBS and collected soon following curettage under sterile conditions, and were divided into two aliquots. One aliquot was fixed in $10 \%$ formaldehyde for terminal deoxynucleotidyl transferase deoxyuridine triphosphate nick end labelling (TUNEL), immunohistochemistry and immunofluorescence, and the other was stored at $-80^{\circ} \mathrm{C}$ for western blot analysis. All samples were collected following the provision of informed consent from the patients, and all associated procedures were performed with the approval of the internal Review and Ethics Boards of Renmin Hospital of Wuhan University.

Cell culture. The human THP-1 peripheral blood acute monocytic leukemia cell line was obtained from the Institute of Biochemistry and Cell Biology, Chinese Academy of Sciences (Shanghai, China). The THP-1 cells were grown in RPMI-1640 medium (Hyclone; GE Healthcare Life Sciences, Logan, UT, USA) supplemented with $10 \%$ fetal bovine serum (FBS; Gibco; Thermo Fisher Scientific, Inc., Waltham, MA, USA), $100 \mathrm{U} / \mathrm{ml}$ penicillin and $100 \mathrm{mg} / \mathrm{ml}$ streptomycin in an atmosphere containing $5 \% \mathrm{CO}_{2}$ at $37^{\circ} \mathrm{C}$. The HTR-8/SVneo cell line, derived from human extravillous trophoblasts, was obtained from the China Center for Type Culture Collection (Wuhan, China). These cells were cultured in Dulbecco's modified Eagle's medium (DMEM; high glucose; Hyclone; GE Healthcare Life Sciences) supplemented with $10 \%$ FBS and antibiotics.

Macrophage polarization and co-culture model. The THP-1 cells were differentiated into macrophages by incubation with $50 \mathrm{ng} / \mathrm{ml}$ phorbol 12-myristate 13-acetate (PMA; Sigma-Aldrich; Merck KGaA, Darmstadt, Germany) for 48 h. Macrophages were confirmed using an immunofluorescence assay with primary antibody against CD68 (Novus Biologicals, LLC, Littleton, CO, USA), and five fields (magnification, $\mathrm{x} 400$ ) were selected for analysis using ImageJ software (version 1.46; National Institutes of Health, Bethesda, MD, USA). A trophoblast and macrophage co-culture model was established to determine the effect of macrophage-derived cytokines on the apoptosis of trophoblast-derived cells. In brief, $1.5 \times 10^{5}$ HTR-8/SVneo cells in $2 \mathrm{ml}$ DMEM containing 10\% FBS were seeded into the lower chambers and $5 \times 10^{5}$ differentiated macrophages (M0 in $1 \mathrm{ml}$ RPMI-1640 with 10\% FBS) were placed into the upper chambers of a Transwell plate (Corning Incorporated, Corning, NY, USA), and cultured for $24 \mathrm{~h}$ at $37^{\circ} \mathrm{C}$ for cell attachment. Subsequently, the upper chambers containing M0 macrophages were placed on top of the lower chambers containing HTR-8/SVneo, followed by incubation at $37^{\circ} \mathrm{C}$ for another $48 \mathrm{~h}$.

Cell apoptosis assessment. Cell apoptosis was assessed using a fluorescein isothiocyanate (FITC)-Annexin V Apoptosis Detection kit (Dojindo Molecular Technologies, Inc., Kumamoto, Japan) and flow cytometry using FACS Canto II (BD Biosciences, Franklin Lakes, NJ, USA). In brief, the trophoblasts were collected and stained with propidium iodide/FITC-Annexin $\mathrm{V}$ for $15 \mathrm{~min}$ at $4^{\circ} \mathrm{C}$ in the dark, followed by the addition of binding buffer and analysis by flow cytometry within $10 \mathrm{~min}$. The data were analyzed using the FlowJo VX10 software (Tree Star, Inc., Ashland, OR, USA). All experiments were performed in triplicate.

Western blot analysis. The cells and tissues were lysed with lysis buffer containing $1 \mathrm{mM}$ phenyl methane sulfonyl fluoride (both from Beyotime Institute of Biotechnology, Haimen, China) and protease and phosphatase inhibitors (21). Total protein was extracted from the supernatants of the cell lysates following incubation in lysis buffer for $30 \mathrm{~min}$ on ice, followed 
by centrifugation at $4^{\circ} \mathrm{C}$ for $15 \mathrm{~min}$ at $13,000 \mathrm{~g}$. The supernatant was collected and the protein concentrations were quantified using a bicinchoninic acid protein assay kit (Beyotime Institute of Biotechnology). Equal quantities of protein (40-60 $\mu \mathrm{g}$ ) were separated by $10 \%$ SDS-PAGE and then transferred onto polyvinylidene difluoride membranes (EMD Millipore, Bedford, MA, USA) at $200 \mathrm{~mA}$. The membranes were blocked in $5 \%$ low-fat milk for $1 \mathrm{~h}$ at room temperature and incubated overnight at $4{ }^{\circ} \mathrm{C}$ with the following primary antibodies: Rabbit anti-B-cell lymphoma 2 (Bcl-2)-associated X protein (Bax; cat. no. 2774; 1:1,000 dilution), rabbit anti-Bcl-2 (cat. no. 2876; 1:1,000 dilution; both from Cell Signaling Technology, Inc., Danvers, MA, USA) and mouse anti-GAPDH (cat. no. 60004-1-Ig; 1:5,000 dilution; ProteinTech Group, Inc., Chicago, IL, USA). Following incubation, the membranes were washed with PBS with $0.1 \%$ Tween-20 (PBST) and incubated with horseradish peroxidase-conjugated secondary antibodies (cat. no. SA00001-1 and SA00001-2; 1:5,000 dilution; goat anti-mouse or goat anti-rabbit; ProteinTech Group, Inc.) for $1 \mathrm{~h}$ at $37^{\circ} \mathrm{C}$. The proteins were detected using a Chemiluminescence Western Detection system (Bio-Rad Laboratories, Inc., Hercules, CA, USA) and visualized using autoradiography. Densitometric analysis of band intensities was performed using ImageJ software (version 1.46).

Immunohistochemistry. Immunohistochemical staining was performed as previously described (22). In brief, formalin-fixed, paraffin-embedded decidual and placental villous tissues were cut into $4-\mu \mathrm{m}$ sections, dewaxed in xylene and rehydrated with an ethanol series of descending grades followed by PBS. Subsequently, the samples were incubated in $3 \%$ hydrogen peroxide for $15 \mathrm{~min}$ at room temperature to block the endogenous peroxidase activity. Antigen retrieval was performed by heating in a microwave oven with sodium citrate buffer. The sections were then incubated in $5 \%$ bovine serum albumin (Sigma-Aldrich; Merck KGaA) for $20 \mathrm{~min}$ at room temperature to block any non-specific binding, followed by incubation with primary antibodies against CD68 (cat. no. NB100-683; 1:100 dilution; Novus Biologicals, LLC), CD86 (cat. no. ab53004; 1:100 dilution), CD163 (cat. no. ab87099; 1:50 dilution; both Abcam, Cambridge, MA, USA), Bax (1:400 dilution) and Bcl-2 (1:400 dilution; both Cell Signaling Technology, Inc.) at $37^{\circ} \mathrm{C}$ for $1 \mathrm{~h}$. The sections were then washed and incubated with goat anti-mouse/rabbit secondary antibody (1:2,000 dilution; ProteinTech Group, Inc.) for $30 \mathrm{~min}$ at $37^{\circ} \mathrm{C}$. Antibody binding was identified as a brown precipitate following staining with 3,3-diaminobenzidine tetrahydrochloride (Dako; Agilent Technologies, Inc., Santa Clara, CA, USA). Images were acquired using an optical microscope at a magnification of $x 400$. Five visual fields with tissue occupying $>80 \%$ of the area were selected for analysis and the number of immuno-positive cells was calculated using ImageJ software (version 1.46).

Immunofluorescence. Double immunofluorescence was performed to evaluate the expression of FasL on CD68 ${ }^{+}$ and $\mathrm{CD}^{+} 6^{+}$macrophages and the distribution of $\mathrm{CD} 68^{+}$ macrophages and $\mathrm{CK} 7^{+}$trophoblasts. In brief, the sections were incubated with primary antibodies against CD68 (1:200 dilution; Novus Biologicals, LLC) or CD86 (1:500 dilution;
Abcam) overnight at $4^{\circ} \mathrm{C}$, followed by incubation with cyanine-3 (Cy3)-conjugated goat anti-mouse antibody (cat. no. BA1031; 1:100 dilution; Boster Biological Technology, Wuhan, China) for $30 \mathrm{~min}$ at $37^{\circ} \mathrm{C}$, followed by incubation with bovine serum albumin for $30 \mathrm{~min}$ at room temperature and then with primary antibodies against FasL (cat. no. sc-33716; 1:100 dilution; Santa Cruz Biotechnology, Inc., Dallas, TX, USA) or CK7 (cat. no. 17513-1-AP; 1:100 dilution; ProteinTech Group, Inc.) at $4^{\circ} \mathrm{C}$ overnight. The sections were then incubated with FITC-conjugated goat anti-rabbit antibody (cat. no. BA1105; 1:100 dilution; Boster Biological Technology) for $30 \mathrm{~min}$ at $37^{\circ} \mathrm{C}$. The sections were washed with TBST and visualized under a fluorescence microscope at a magnification of $\mathrm{x} 400$. Cy3 was detected as red and FITC as green fluorescence, and the blue fluorescence signal represented the nuclear DNA stained by 4',6-diamidino-2-phenylindole (DAPI). Five random fields from stained sections were selected. The proportion of $\mathrm{CD}^{+} 8^{+}$and $\mathrm{CD}^{+} 6^{+}$macrophages with FasL was calculated as the number of $\mathrm{CD}^{2} 8^{+} \mathrm{FasL}{ }^{+}$or $\mathrm{CD} 6^{+} \mathrm{FasL}^{+}$cells divided by the number of $\mathrm{CD}^{2} 8^{+}$or $\mathrm{CD} 86^{+}$cells in the field using ImageJ software (version 1.46).

TUNEL. Apoptosis in the decidual and placental villous tissues was detected using an in situ TUNEL detection kit (Promega Corporation, Madison, WI, USA). In brief, the paraffinized sections were dewaxed in xylene, rehydrated and washed in PBS, and then stained according to the manufacturer's protocol. The nuclei were visualized with $0.1 \mu \mathrm{g} / \mathrm{ml}$ DAPI (Beyotime Institute of Biotechnology) in PBS at $30^{\circ} \mathrm{C}$ for $30 \mathrm{~min}$. Cells containing the characteristic fragmented nuclear chromatin and brown nuclear staining were considered to be apoptotic. The apoptotic index was calculated as follows: Apoptotic index $=$ (number of TUNEL - positive nuclei)/(number of total nuclei) x $100 \%$. Images were captured with a fluorescence microscope at a magnification of x400 and analyzed using ImageJ software (version 1.46).

Flow cytometry. The THP-1 cells stimulated with PMA or PBS were stained with anti-FasL antibody to determine the expression of FasL on macrophages. In brief, THP-1 cells were collected following stimulation with PMA or PBS, centrifuged at $300 \times \mathrm{g}$ for $10 \mathrm{~min}$ at room temperature and resuspended in PBS. The cells $\left(1 \times 10^{6} /\right.$ tube) were stained with primary antibody against FasL (cat. no. sc-33716; 1:100 dilution; Santa Cruz Biotechnology, Inc.) overnight at $4^{\circ} \mathrm{C}$, and then incubated with FITC-conjugated Affinipure goat anti-rabbit immunoglobulin G (H+L; cat. no. SA00003-2; 1:100 dilution; ProteinTech Group, Inc.) for $1 \mathrm{~h}$ at $37^{\circ} \mathrm{C}$. Finally, the fluorescence of the cells was analyzed by flow cytometry (FACS Canto II; BD Biosciences).

Statistical analysis. Values were expressed as the mean \pm standard error of the mean. Statistical analyses were performed using SPSS 19.0 (IBM Corp., Armonk, NY, USA) using Student's t-test or one-way analysis of variance with Bonferroni's post hoc test. The clinical characteristics were compared between the normal and RM patients using the Kruskal-Wallis test. The experiments were repeated at least three times for each group. $\mathrm{P}<0.05$ was considered to indicate a statistically significant difference. 
Table I. Demographic and clinical characteristics of the study population.

\begin{tabular}{lccc}
\hline Characteristics & Control group $(\mathrm{n}=34)$ & Abortion group $(\mathrm{n}=26)$ & RM group (n=21) \\
\hline Age (years) & $29.86 \pm 4.03$ & $28.98 \pm 3.59$ & $30.08 \pm 4.23$ \\
BMI $\left(\mathrm{kg} / \mathrm{m}^{2}\right)$ & $21.38 \pm 3.13$ & $22.09 \pm 2.68$ & $21.28 \pm 3.52$ \\
Gestation age (weeks) & $8.49 \pm 1.45$ & $8.43 \pm 1.28$ & $8.33 \pm 1.78$ \\
No. of miscarriages & $0.65 \pm 0.12$ & $1.43 \pm 0.25^{\mathrm{a}}$ & $2.63 \pm 0.41^{\mathrm{a}}$ \\
No. of live births & $1.51 \pm 0.34$ & $0.96 \pm 0.23^{\mathrm{a}}$ & $0.00 \pm 0.00^{\mathrm{a}}$ \\
\hline
\end{tabular}

${ }^{\mathrm{a}} \mathrm{P}<0.01$. Values are mean $\pm \mathrm{SD}$. RM, recurrent miscarriage; BMI, body mass index.

\section{Results}

Baseline characteristics of the control, abortion and RM groups. To examine the expression and distribution of macrophages in spontaneous abortion and in miscarriages in terms of recurrence, three groups were included in the present study. The clinical characteristics of the recruited patients are listed in Table I. No significant differences were observed among the three groups in terms of maternal age, BMI and gestational age. However, the number of miscarriages in the RM group and abortion group were significantly higher and the numbers of live births were significantly lower compared with those in the control group ( $\mathrm{P}<0.01$ for both).

Comparison of macrophage population between the control, abortion and RM groups. The decidual tissues from the three groups were found to contain macrophages that were stained with the primary antibody against CD68. The majority of the $\mathrm{CD}^{+} 8^{+}$macrophages from subjects with RM were distributed in the cytoplasm of decidual stromal cells and certain macrophages dispersed around blood vessels and glands, and the localization of $\mathrm{CD} 68^{+}$macrophages in the decidua of the control subjects and abortion group was similar to that of the subjects from the RM group (Fig. 1A). Cells positive for CD163 (an M2 marker) and CD86 (an M1 marker) were apparent in the three groups, mainly in the cytoplasm of stromal cells (Fig. 1A). In the $\mathrm{RM}$ patients, the $\mathrm{CD}^{+} 8^{+}$macrophage population in the decidual tissues was significantly increased, accompanied by an increased $\mathrm{CD} 6^{+}$macrophage population (Fig. 1B and C) and a reduced $\mathrm{CD}_{163}{ }^{+}$macrophage population (Fig. 1D), compared with the control group. In the abortion group, the $\mathrm{CD} 68^{+}$macrophage population did not differ significantly, and the expression levels of the $\mathrm{CD}^{+} 6^{+}$and $\mathrm{CD} 163^{+}$macrophage populations were similar to those in the RM group (Fig. 1C). These results indicated that increased macrophage infiltration and an aberrant macrophage population in the decidua may be associated with miscarriage.

Comparison of macrophage distribution among the control, abortion and RM groups. In the present study, CK7 was selected as a trophoblast marker. As presented in Fig. 2, the immunofluorescence analysis indicated that the number of $\mathrm{CD}^{+} 8^{+}$cells was significantly higher in the RM patients compared with that in control subjects, which is in accordance with the results of the immunohistochemical analysis (Fig. 1A and B). Furthermore, CD68 ${ }^{+}$macrophages were located in the periphery of the trophoblast cells from the subjects with normal pregnancies, whereas in the decidual tissues of abortion and RM patients, significant infiltration of $\mathrm{CD} 68^{+}$macrophages into $\mathrm{CK}^{+}$trophoblast cells was observed (Fig. 2). These results demonstrated that the macrophage distribution was significantly altered in the women in the abortion and RM groups.

Comparison of apoptosis among the control, abortion and RM groups. To investigate the association between apoptosis and fetal loss, TUNEL was used to detect cell apoptosis and western blot analysis was used to determine the expression of apoptosis-promoting protein Bax and the anti-apoptotic protein Bcl-2 in the decidual and placental villous tissues. The TUNEL assay revealed that the proportion of cells with brown nuclear staining (apoptotic cells) and the associated apoptotic index was significantly higher in the abortion and RM groups compared with that in the control group (Fig. 3A and B), indicating that apoptosis in the decidua from the abortion and RM patients was higher than that from the controls. Furthermore, the results of the western blot analysis revealed that the protein level of $\mathrm{Bcl}-2$ was reduced and the protein level of Bax was increased compared with levels in the control group, which was further confirmed by the immunohistochemical and immunofluorescence staining (Fig. 3C-F). As expected, similar results were observed in the placental villous tissues (Fig. 4A-E). These results demonstrated that elevated apoptosis in the decidual and placental villous tissues is associated with fetal loss.

Comparison of the expression levels of FasL on macrophages among the control, abortion and RM groups. As FasL is able to induce apoptosis (18), the expression of FasL has been previously detected in macrophages, with patients with RM exhibiting elevated expression of FasL (15-17). The present study performed dual immunofluorescence analysis of CD68 and FasL to identify the expression of FasL on macrophages in the decidua. The results (Fig. 5A-D) indicated that CD68 ${ }^{+}$ $\mathrm{dM} \Phi$ expressed minimal FasL protein, with only a weak signal in normal women; by contrast, the decidua was rich in $\mathrm{FasL}^{+}$ macrophages in the RM patients (Fig. 5A and C). In addition, the expression of FasL on $\mathrm{CD}^{+} 6^{+}$macrophages was detected by dual immunofluorescence. The proportion of $\mathrm{CD}^{2} 6^{+} \mathrm{FasL}^{+}$ macrophages in the abortion and RM groups were significantly higher than that in the control group (Fig. 5B and D). These results demonstrated that the abnormal expression of 
A
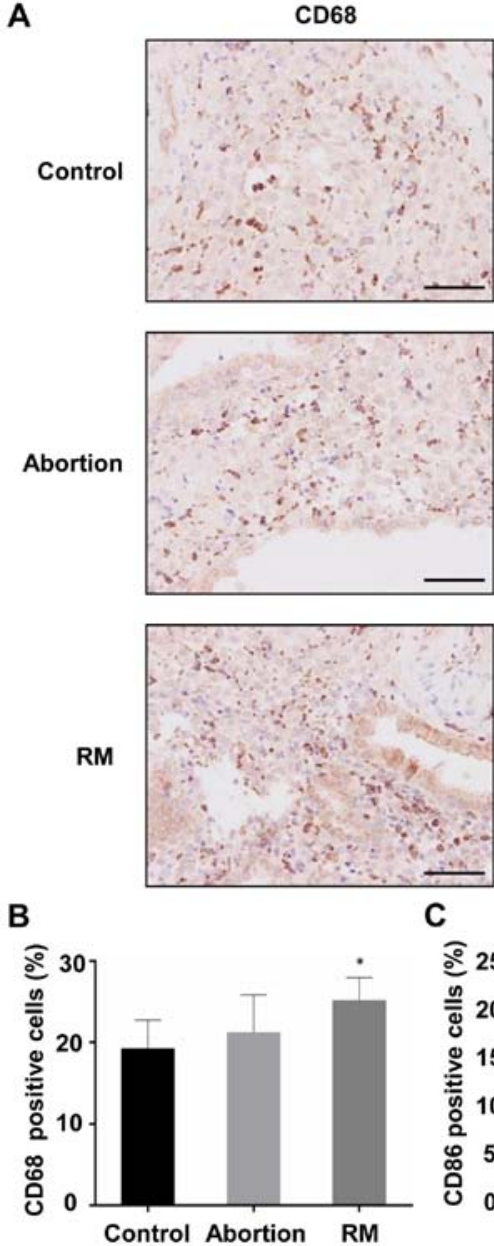
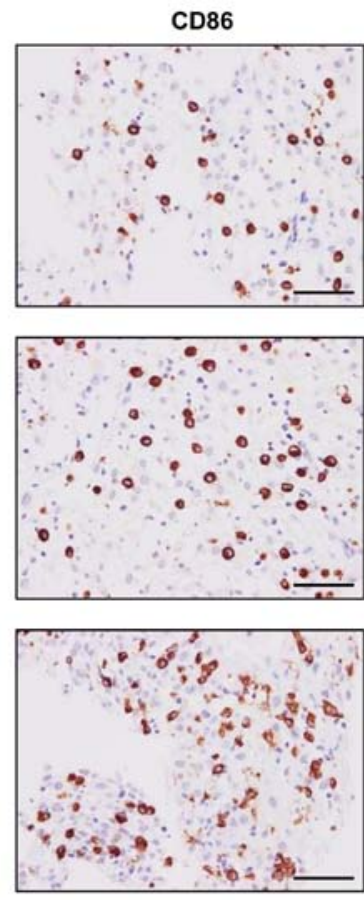

C

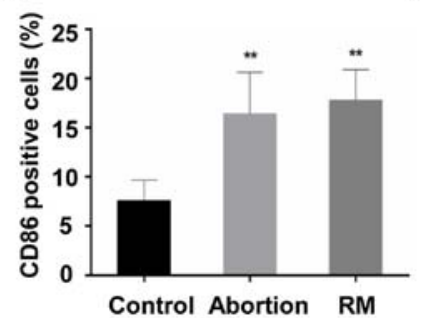

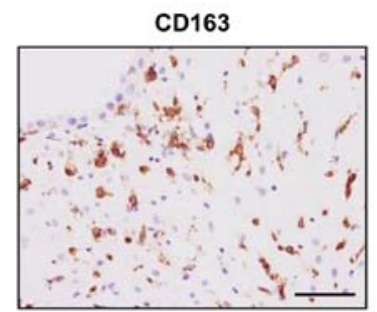
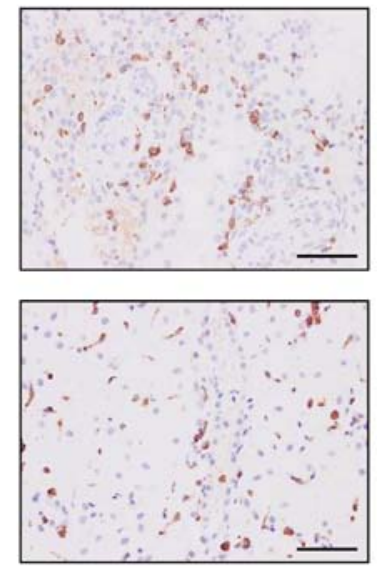

D

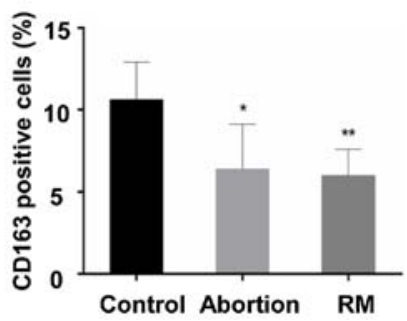

Figure 1. Comparison of the macrophage population among the control, abortion and RM groups. (A) Macrophage populations of the maternal decidua of the RM $(\mathrm{n}=21)$, abortion $(\mathrm{n}=26)$ and control group $(\mathrm{n}=34)$ were determined by immunohistochemistry with primary antibody against CD68, CD86 and CD163. Analysis of (B) $\mathrm{CD}^{+} 8^{+}$, (C) $\mathrm{CD} 6^{+}$and (D) CD163 ${ }^{+}$cells in decidual tissues. Scale bars, $100 \mu \mathrm{m}$. ${ }^{*} \mathrm{P}<0.05,{ }^{* *} \mathrm{P}<0.01$ vs. the control group. RM, recurrent miscarriage.
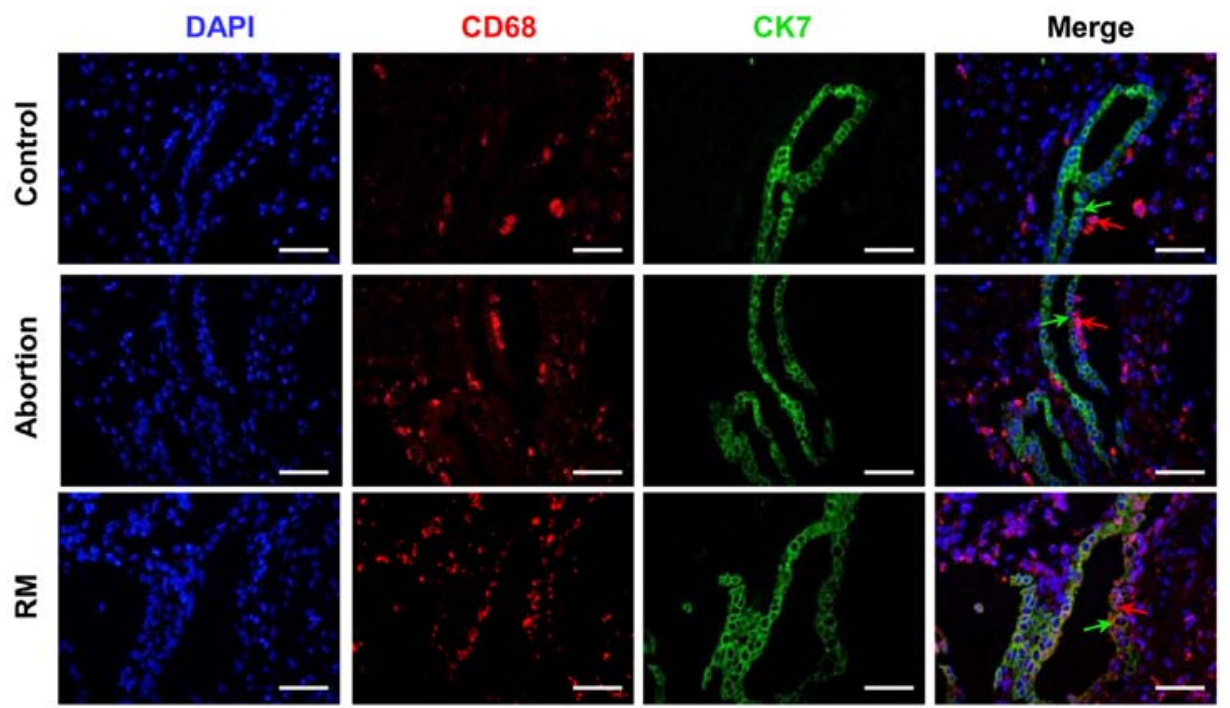

Figure 2. Comparison of macrophage distribution among the control, abortion and RM groups. Distribution of macrophages amongst trophoblasts was evaluated using dual immunofluorescence with primary antibodies against CD68 and CK7. The blue signal represents nuclear DNA staining with DAPI, the red signal represents CD68 and the green signal represents CK7; green arrows represent CK7 $7^{+}$trophoblasts and red arrows represent $\mathrm{CD} 68^{+}$macrophages. Scale bars, $100 \mu \mathrm{m}$; RM, recurrent miscarriage; DAPI, 4',6-diamidino-2-phenylindole.

FasL on $\mathrm{dM} \Phi$ may be associated with miscarriage, and even RM.
Effect of macrophages on the apoptosis of trophoblast cells. As significantly increased macrophage infiltration was 
A

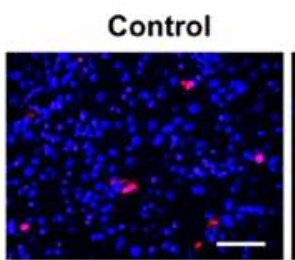

Abortion

RM

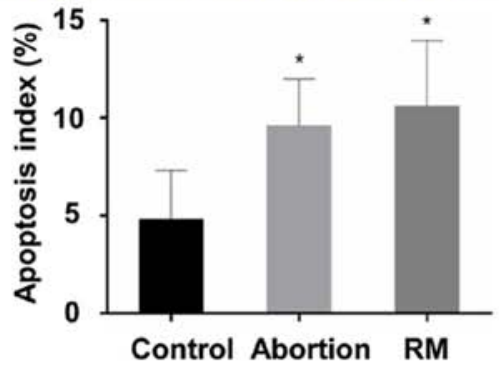

B

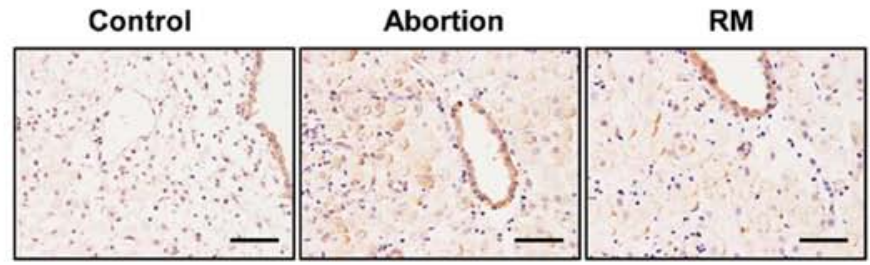

C

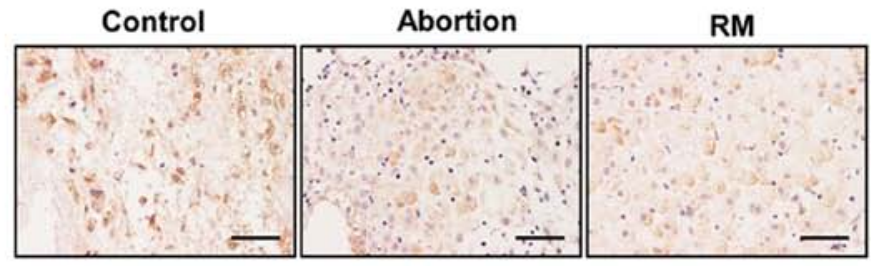

D
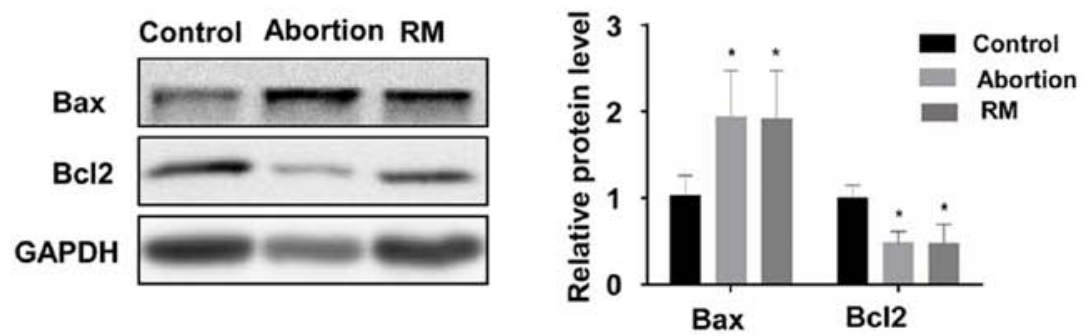

E

DAPI

CK7

Bax

Merge
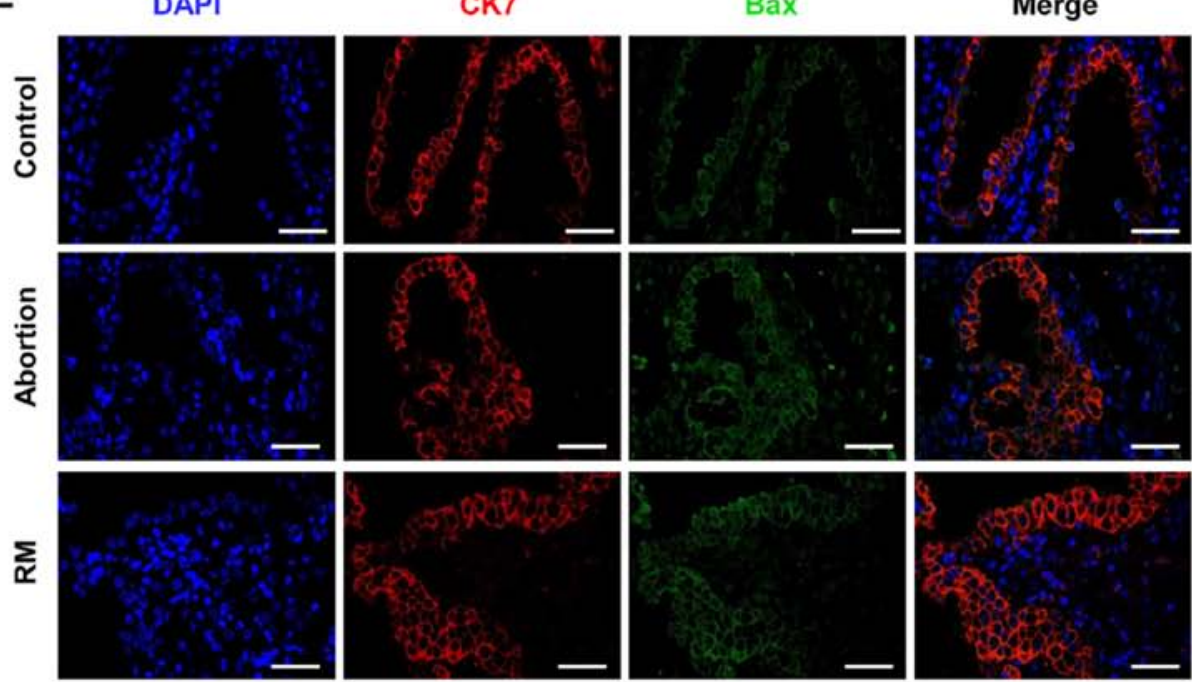

Figure 3. Comparison of levels of apoptosis in decidual tissues among the control, abortion and RM groups. (A) Apoptosis was determined by terminal deoxynucleotidyl transferase deoxyuridine triphosphate nick end labelling in decidual tissues from women in the normal pregnancy $(\mathrm{n}=34)$, abortion $(\mathrm{n}=26)$ and RM ( $\mathrm{n}=21$ ) groups, respectively. Distributions of (B) Bax and (C) Bcl-2 in decidual tissues were detected by immunohistochemistry (magnification, $\mathrm{x} 400$ ). (D) Protein levels of Bax and Bcl-2 in decidual tissues were measured by western blotting. (E) The expression of Bax on trophoblasts was analyzed by dual immunofluorescence (magnification, $\mathrm{x} 400$ ). 
$\mathbf{F}$
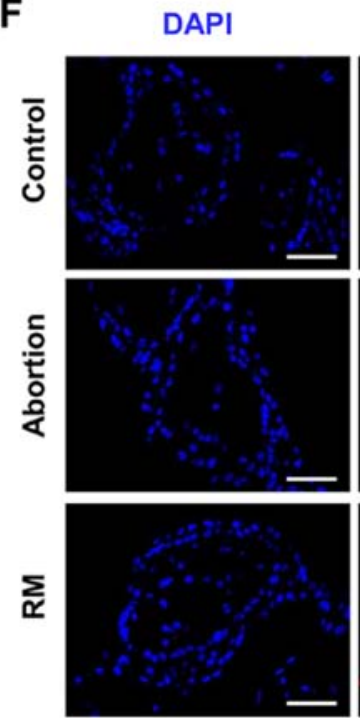

CK7
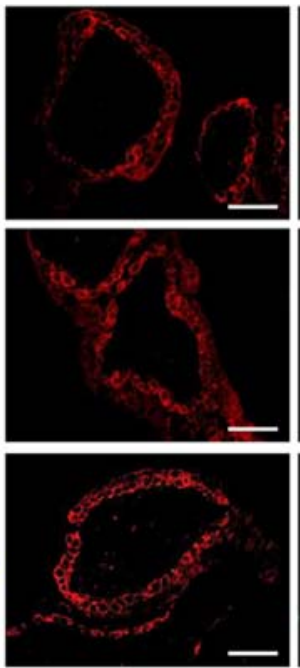
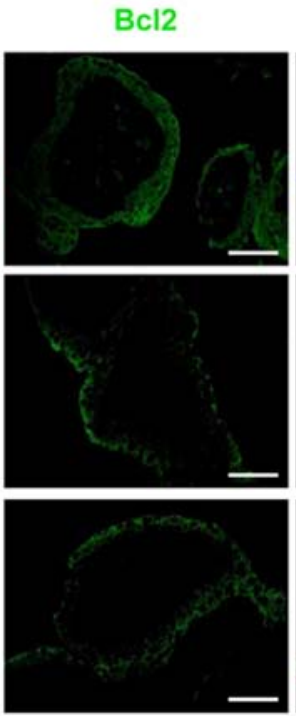

Merge
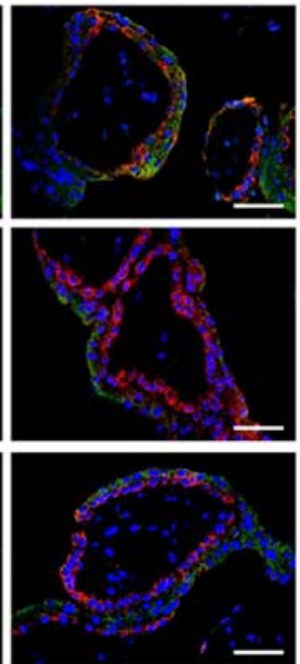

Figure 3. Continued. (F) The expression of Bcl-2 on trophoblasts was analyzed by dual immunofluorescence (magnification, $\mathrm{x} 400$ ). Scale bars, $100 \mu \mathrm{m}$. ${ }^{*} \mathrm{P}<0.05$ vs. the control group. RM, recurrent miscarriage; Bcl-2, B-cell lymphoma 2; Bax, Bcl-2-associated X protein; DAPI, 4',6-diamidino-2-phenylindole.

observed in the abortion and RM patients (Fig. 1A and B), and as macrophages are able to induce apoptosis (23), a trophoblast and macrophage co-culture model was used to determine whether macrophages induce apoptosis in trophoblasts. As presented in Fig. 6A, both the inactivated and activated THP-1 cells (M0) expressed CD68, although the expression of CD68 in the activated THP-1 cells was increased (Fig. 6A). In addition, the expression level of FasL was increased in the M0 macrophages (Fig. 6B and C), and the co-culture model demonstrated that M0 macrophages promoted the apoptosis of trophoblast-derived cells (Fig. 6D and E). In order to verify the role of FasL in macrophage-induced trophoblast apoptosis, an intervention experiment was performed, in which anti-FasL blocking antibody or isotype control antibody (R\&D Systems, Inc., Minneapolis, MN, USA) was added to the co-culture model. Macrophages induced significant cell apoptosis, whereas the addition of anti-FasL blocking antibody significantly inhibited this effect (Fig. 6D and E). These results indicated that macrophages mediate the apoptosis of trophoblast cells through FasL-dependent pathways.

\section{Discussion}

It is generally considered that macrophages are essential for the establishment and maintenance of pregnancy, as they are involved in diverse processes, including blood vessel remodeling, immune tolerance, immunomodulation of maternal decidual lymphocytes and parturition initiation (24-27). Comprising 20-25\% of the decidual leukocyte population in early pregnancy (2), $\mathrm{dM} \Phi$ are involved in vascular remodeling, inducing the apoptosis of damaged cells, removal of apoptotic cell debris and the elimination of invading pathogens (28). A previous study reported that $\mathrm{dM} \Phi$ may be polarized to the M2 subtype to exert important roles in maintaining immune tolerance in early pregnancy (7), whereas macrophages polarized into the M1 subtype may promote RM (8). In the present study, CD68 (a marker for macrophages), CD163 (M2 marker) and CD86 (M1 marker) were used to characterize macrophage populations in the decidua, and the results indicated that M1 macrophages were significantly higher and M2 macrophages were decreased in the RM and abortion groups compared with those in the control group, which was in accordance with the results of earlier studies $(3-5,8)$. During pregnancy, the invading trophoblast cell is in close contact with maternal immune cells, including T lymphocytes, natural killer cells and macrophages (29). A previous study reported that macrophages significantly infiltrated the trophoblasts in spontaneous miscarriage (8), although the distribution of macrophages in RM was unclear. In the present study, dual immunofluorescence staining against CD68 and CK7 revealed the presence of macrophage infiltration into trophoblast cells in the RM group. These results indicated that aberrant infiltration and the distribution of $\mathrm{dM} \Phi$ may be associated with the unfortunate pregnancy outcomes of RM and abortion in women.

During pregnancy, the turnover of placenta depends on the functional loss of trophoblast cells by apoptosis, and the trophoblast cells are removed and replaced with a younger population in this physiological process $(30,31)$; however, decidual apoptosis may result in a series of cellular dysfunctions, which may impair the course of pregnancy and lead to RM (32). Several studies have reported on the association between apoptosis deregulation and RM $(10,11)$. In the present study, the apoptosis of decidual and placental villous tissues was confirmed by TUNEL staining. The results demonstrated a significant increase in the apoptotic index in the decidual and placental villous tissues of the abortion and RM groups, accompanied by decreased protein levels of Bcl-2 and increased protein levels of Bax, compared with those in the control group, which was in accordance with previous studies $(33,34)$. These results suggest that aberrant apoptosis in decidual and placental villous tissues may be a cause of embryo loss.

The Fas/FasL system is one of the major apoptotic pathways in cells and tissues, and the binding of the Fas receptor by FasL activates a cascade of intracellular proteolytic enzymes, leading to the apoptosis of Fas-bearing cells (35). A previous study indicated that excess macrophages in the preeclamptic 
A

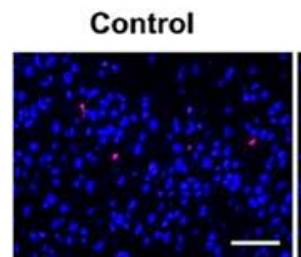

Abortion

RM

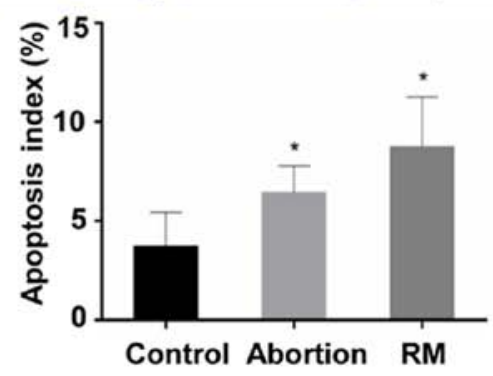

B

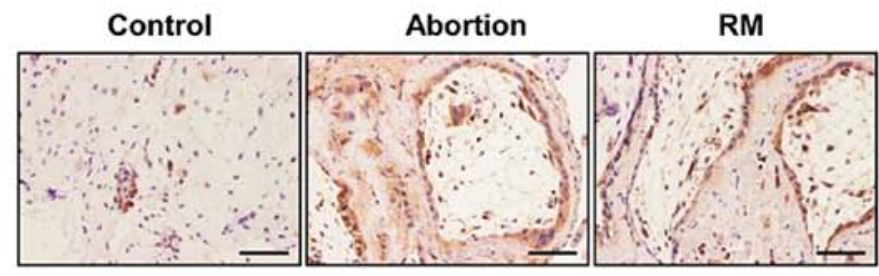

C

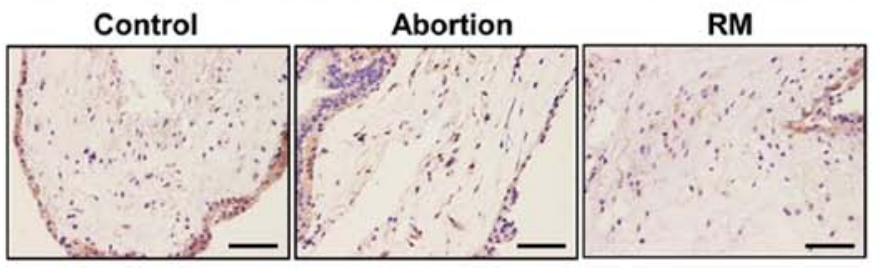

D
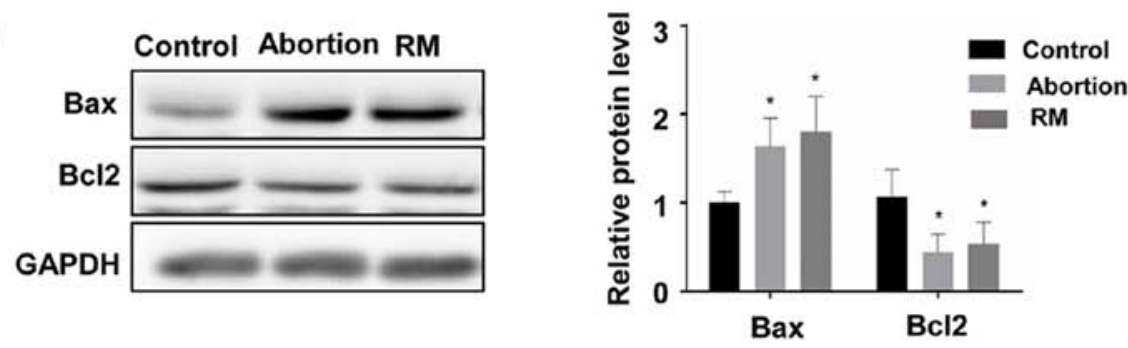

E

DAPI

CK7
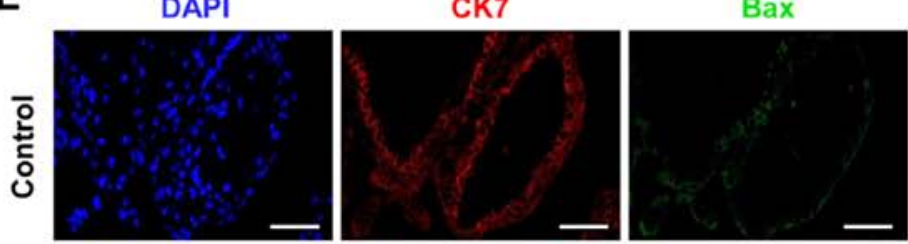

Merge
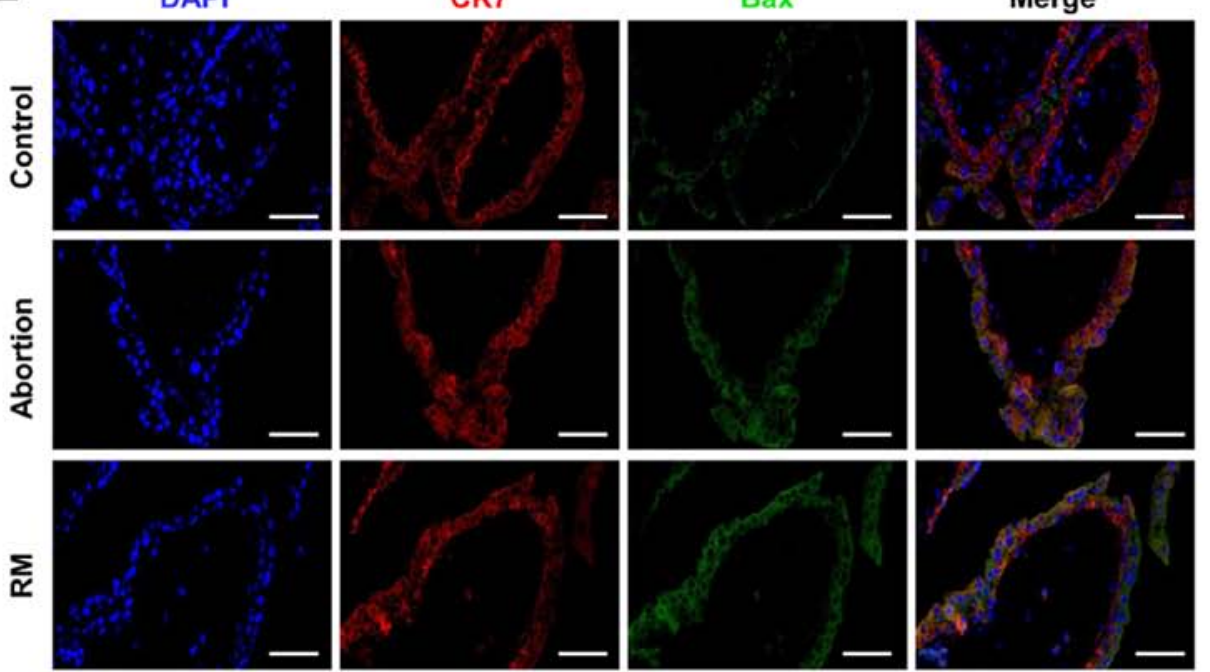

Figure 4. Comparison of levels of apoptosis in the placental villous tissues among control, abortion and RM groups. (A) Apoptosis was determined by terminal deoxynucleotidyl transferase deoxyuridine triphosphate nick end labelling in placental villous tissues from women in the normal pregnancy ( $\mathrm{n}=34)$, abortion $(\mathrm{n}=26)$ and RM ( $\mathrm{n}=21)$ groups, respectively. Distributions of (B) Bax and (C) Bcl-2 in placental villous tissue were detected by immunohistochemistry (magnification, x400). (D) Protein levels of Bax and Bcl-2 in placental villous tissues were measured by western blotting. (E) The expression of Bax on trophoblasts was analyzed by dual immunofluorescence (magnification, $\mathrm{x} 400$ ). 
$\mathbf{F}$
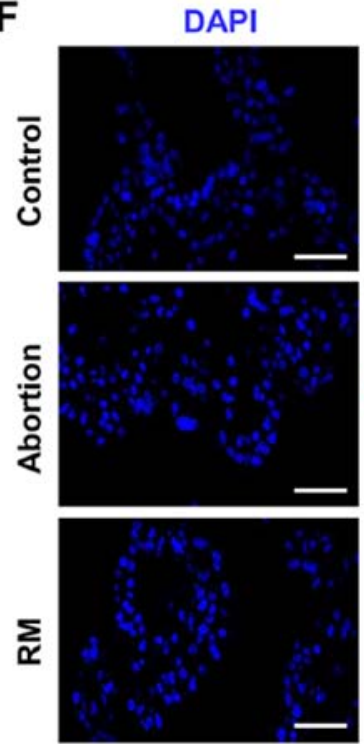

CK7
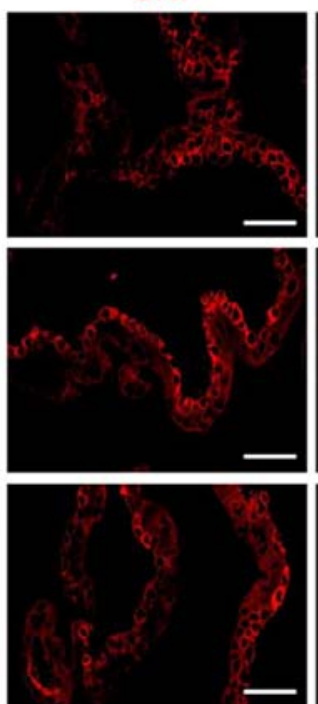

$\mathrm{Bcl} 2$
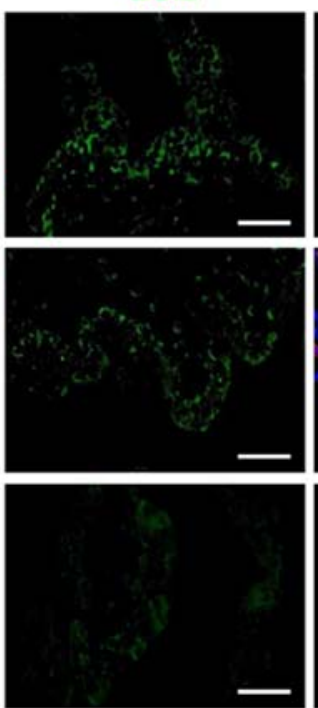

Merge
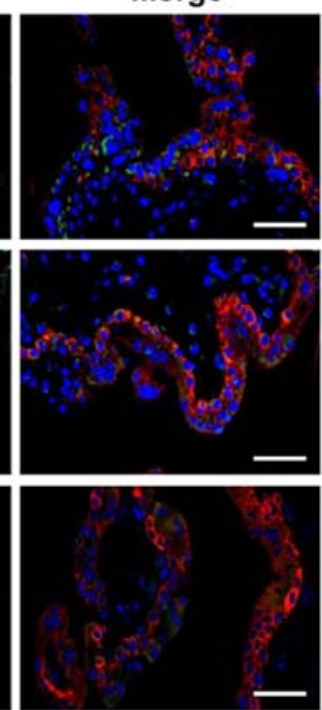

Figure 4. Continued. (F) The expression of Bcl-2 on trophoblasts was analyzed by dual immunofluorescence (magnification, $\mathrm{x} 400$ ). Scale bars, $100 \mu \mathrm{m}$. ${ }^{*} \mathrm{P}<0.05$ vs. the control group. RM, recurrent miscarriage; Bcl-2, B-cell lymphoma 2; Bax, Bcl-2-associated X protein; DAPI, 4',6-diamidino-2-phenylindole.

A

DAPI

CD68

FasL

Merge

C
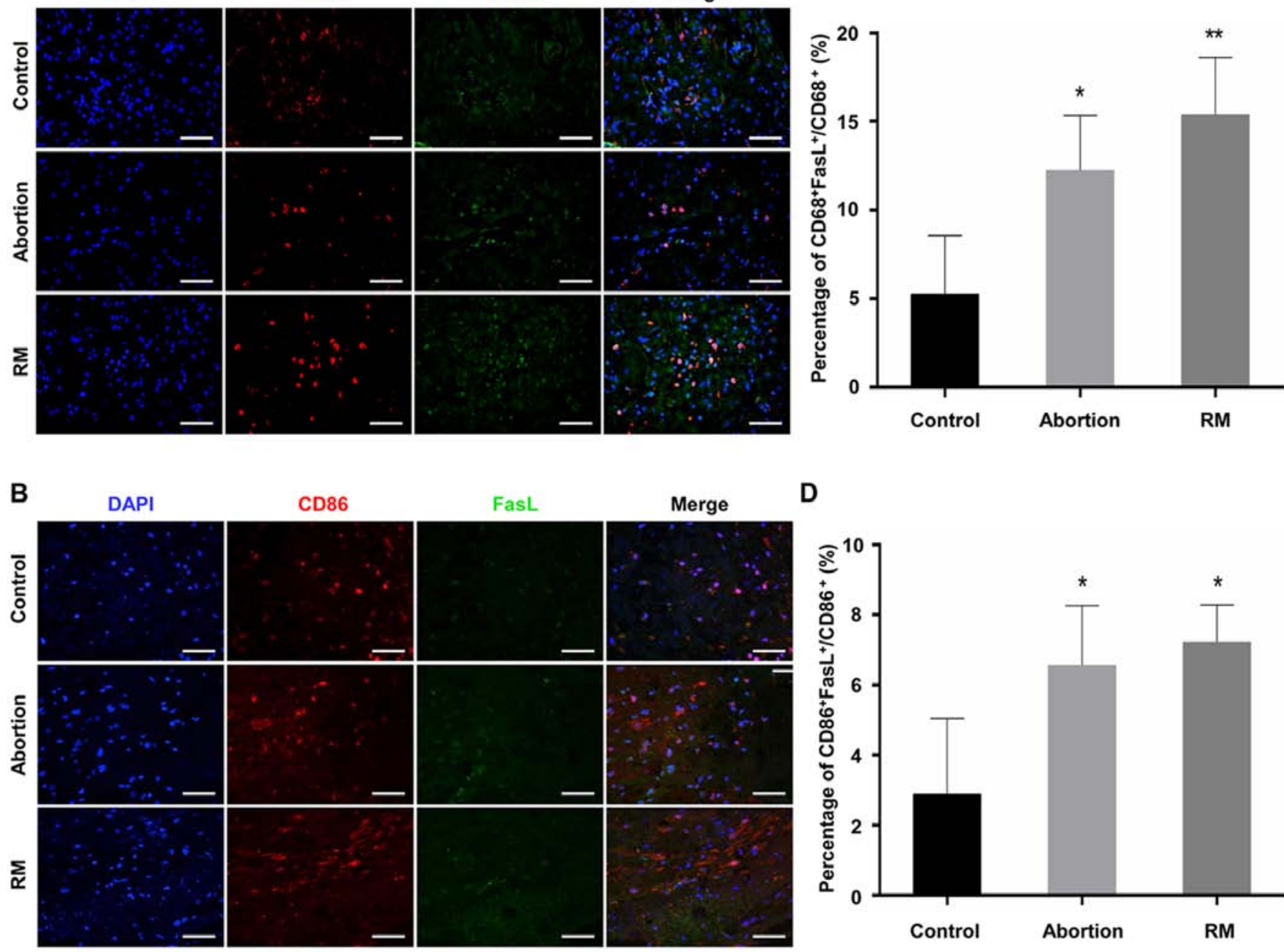

D

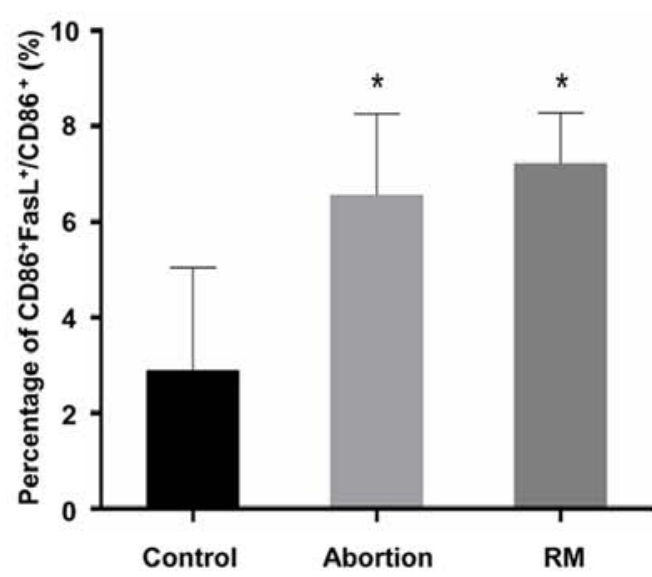

Figure 5. Comparison of the expression of FasL on macrophages among the control, abortion and RM groups. The expression of FasL on macrophages and M1 macrophages in decidual tissues was evaluated using dual immunofluorescence against (A) CD68 and FasL and (B) CD86 and FasL. The blue signal represents nuclear DNA staining by DAPI, red signal represents CD68, green signal represents FasL. Evaluation of FasL on (C) CD68 ${ }^{+}$macrophages and (D) CD86 ${ }^{+}$ macrophages calculated the number of $\mathrm{CD} 68^{+} \mathrm{FasL}^{+}$or $\mathrm{CD} 86^{+} \mathrm{FasL}^{+}$cells divided by the number of $\mathrm{CD} 68^{+}$or $\mathrm{CD} 86^{+}$cells in the field using Image $\mathrm{J}$ software. Scale bars, $100 \mu \mathrm{m} .{ }^{*} \mathrm{P}<0.05,{ }^{* *} \mathrm{P}<0.01$ vs. the control group. RM, recurrent miscarriage; FasL, Fas ligand; DAPI, 4',6-diamidino-2-phenylindole. 
A

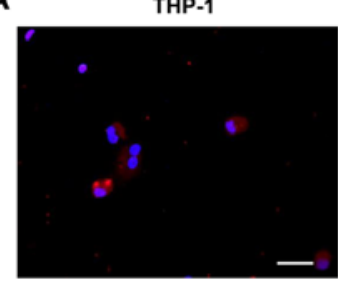

D

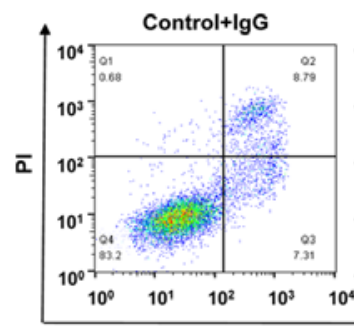

THP-1+PMA

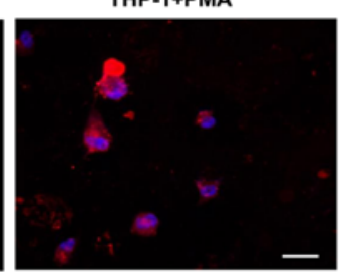

B

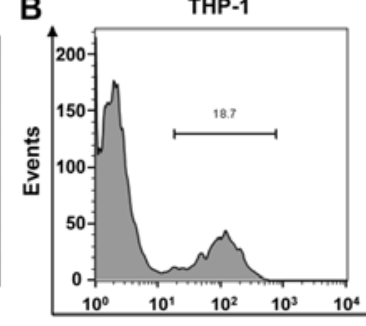

THP-1+PMA

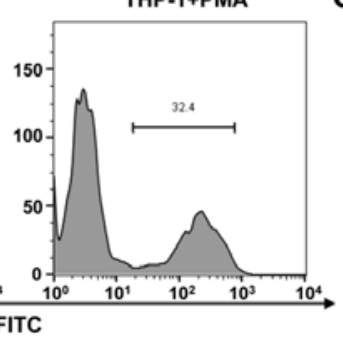

C

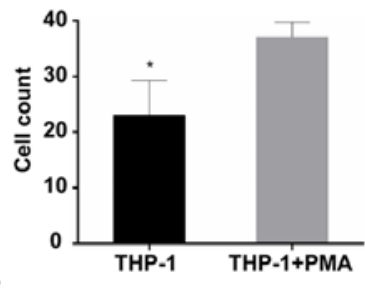

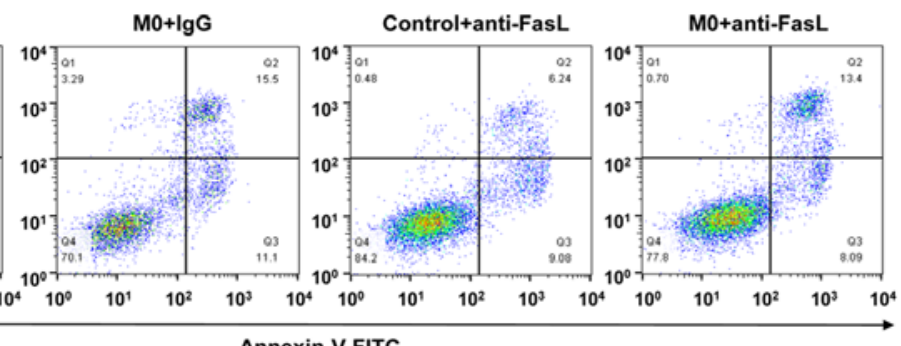

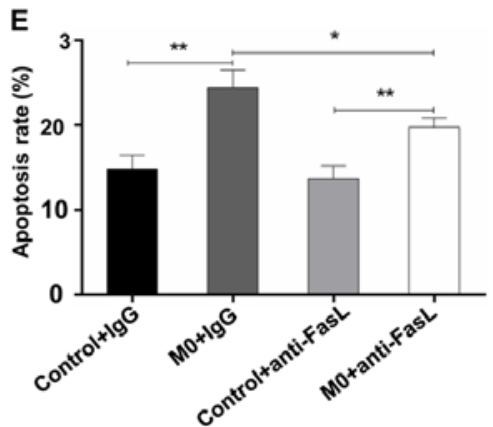

Figure 6. Effect of macrophages on the apoptosis of trophoblast cells. (A) Trophoblast and macrophage co-culture model to determine whether macrophage induce the apoptosis of trophoblasts. Immunofluorescence staining of CD68 was performed in THP-1 cells stimulated with PMA or PBS, DAPI staining (blue) was performed to visualize cell nuclei (magnification, x400). (B) Flow cytometry and (C) quantification of the expression of FasL on THP-1 cells stimulated with PMA or PBS. Trophoblast cells were co-cultured with macrophages in the presence of anti-FasL antibody or isotype control. (D) Flow cytometry and (E) quantification of apoptosis of the HTR-8/SVneo cell line. Scale bars, $100 \mu \mathrm{m}$; ${ }^{*} \mathrm{P}<0.05$; ${ }^{* *} \mathrm{P}<0.01$. PMA, phorbol 12-myristate 13 -acetate; PI, propidium iodide; FITC, fluorescein isothiocyanate; DAPI, 4',6-diamidino-2-phenylindole; M0, differentiated macrophages; FasL, Fas ligand.

decidua induced trophoblast apoptosis (14), and patients with RM exhibit higher expression of FasL (15-17). In addition, FasL is known to induce apoptosis (18), and macrophages induced FasL-mediated apoptosis in a model of pulmonary silicosis (19) and chronic demyelinated neuropathy (20). A previous study by Guenther et al (8) suggested the potential role of FasL on macrophages in trophoblast apoptosis in spontaneous miscarriage; however, the role of aberrant expression of FasL on macrophages in miscarriages, in terms of recurrence, and its exact effect on the apoptosis of trophoblast cells remain to be fully elucidated. In the present study, double immunofluorescence staining for CD68 and FasL was performed in the decidua. The results indicated that $\mathrm{dM} \Phi$ became strongly positive for FasL, a ligand which induces apoptosis in Fas-expressing extravillous trophoblasts (17). The co-localization of CD68 and FasL suggested that macrophages may contribute to the production and/or release of FasL. In addition, the co-culture experiment revealed that macrophages promoted the apoptosis of trophoblast cells, which was consistent with a study by Guirelli et al (23), and this effect was reversed by FasL neutralization antibody, which was in agreement with previous studies $(19,20)$, supporting the hypothesis that macrophages induce the apoptosis of trophoblast cells through the release of FasL (23).

In conclusion, the results of the present study indicate that abnormal macrophage infiltration and distribution, in addition to the aberrant expression of FasL on $\mathrm{dM} \Phi$ are associated with spontaneous abortion and RM. In vitro assays further demonstrated that macrophages induced apoptosis in trophoblast cells by FasL mediation. Therefore, it is possible to conclude that the aberration of macrophage-induced, FasL-mediated apoptosis may represent one of the mechanisms leading to spontaneous abortion and RM. However, it was not possible to conclude whether the abnormal macrophage profile and trophoblast apoptosis were a cause or a result of the miscarriage process. In addition, flow cytometric analysis provides an effective way of precisely detecting FasL on $\mathrm{dM} \Phi$ in single cell suspensions made from decidua, and this warrants further investigation. Additional investigations are also required to clarify the specific effect of FasL on the interaction between macrophages and trophoblasts.

\section{Acknowledgements}

Not applicable.

\section{Funding}

The present study was supported by the National Natural Science Foundation of China (grant nos. 81771618, 81771662 and 81701412) and the National Key Research and Development Program of China (grant nos. 2016YFC1000600 and 2018YFC1002804).

\section{Availability of data and materials}

All data generated or analyzed during this study are included in this published article.

\section{Authors' contributions}

YC and JY were involved in study design and revision of the manuscript. JD and TY wrote the manuscript. JD, TY and NY performed the experiments. JD, TY and NY analyzed and interpreted the data. All authors read and approved the final manuscript. 


\section{Ethics approval and consent to participate}

Written informed consent was obtained from all the patients and the research protocols were approved by the Ethics Committee of Renmin Hospital of Wuhan University.

\section{Patient consent for publication}

Informed consent was obtained from the subjects participating in the present study.

\section{Competing interests}

The authors declare that they have no competing interests.

\section{References}

1. Rai R and Regan L: Recurrent miscarriage. Lancet 368: 601-611, 2006.

2. Heikkinen J, Möttönen M, Komi J, Alanen A and Lassila O: Phenotypic characterization of human decidual macrophages. Clin Exp Immunol 131: 498-505, 2003.

3. Kolben TM, Rogatsch E, Vattai A,Hester A, Kuhn C, Schmoeckel E, Mahner S, Jeschke U and Kolben T: PPAR $\gamma$ expression is diminished in macrophages of recurrent miscarriage placentas. Int J Mol Sci 19: 1872, 2018.

4. Tsao FY, Wu MY, Chang YL, Wu CT and Ho HN: M1 macrophages decrease in the deciduae from normal pregnancies but not from spontaneous abortions or unexplained recurrent spontaneous abortions. J Formos Med Assoc 117: 204-211, 2018.

5. Quack KC, Vassiliadou N, Pudney J, Anderson DJ and Hill JA Leukocyte activation in the decidua of chromosomally normal and abnormal fetuses from women with recurrent abortion. Hum Reprod 16: 949-955, 2001.

6. Colin S, Chinetti-Gbaguidi G and Staels B: Macrophage phenotypes in atherosclerosis. Immunol Rev 262: 153-166, 2014.

7. Gustafsson C, Mjösberg J, Matussek A, Geffers R, Matthiesen L, Berg G, Sharma S, Buer J and Ernerudh J: Gene expression profiling of human decidual macrophages: Evidence for immunosuppressive phenotype. PLoS One 3: e2078, 2008.

8. Guenther S, Vrekoussis T, Heublein S, Bayer B, Anz D, Knabl J, Navrozoglou I, Dian D, Friese K, Makrigiannakis A and Jeschke U: Decidual macrophages are significantly increased in spontaneous miscarriages and over-express FasL: A potential role for macrophages in trophoblast apoptosis. Int J Mol Sci 13: 9069-9080, 2012.

9. Jerzak M and Bischof P: Apoptosis in the first trimester human placenta: The role in maintaining immune privilege at the maternal-foetal interface and in the trophoblast remodelling. Eur J Obstet Gynecol Reprod Biol 100: 138-142, 2002.

10. Abrahams VM, Kim YM, Straszewski SL, Romero R and Mor G: Macrophages and apoptotic cell clearance during pregnancy. Am J Reprod Immunol 51: 275-282, 2004.

11. Crocker IP, Cooper S, Ong SC and Baker PN: Differences in apoptotic susceptibility of cytotrophoblasts and syncytiotrophoblasts in normal pregnancy to those complicated with preeclampsia and intrauterine growth restriction. Am J Pathol 162: 637-643, 2003.

12. Lettau M, Paulsen M, Kabelitz D and Janssen O: FasL expression and reverse signalling. Results Probl Cell Differ 49: 49-61, 2009.

13. Arai $M$, Yoshioka S, Nishimura $R$ and Okuda $K$ : FAS/FASL-mediated cell death in the bovine endometrium. Anim Reprod Sci 151: 97-104, 2014.

14. Huang SJ, Chen CP, Schatz F, Rahman M, Abrahams VM and Lockwood CJ: Pre-eclampsia is associated with dendritic cell recruitment into the uterine decidua. J Pathol 214: 328-336, 2008.

15. Banzato PC, Daher S, Traina E, Torloni MR, GueuvoghlanianSilva BY, Puccini RF, Pendeloski KP and Mattar R: FAS and FAS-L genotype and expression in patients with recurrent pregnancy loss. Reprod Sci 20: 1111-1115, 2013.

16. Choi HK, Choi BC, Lee SH, Kim JW, Cha KY and Baek KH: Expression of angiogenesis- and apoptosis-related genes in chorionic villi derived from recurrent pregnancy loss patients. Mol Reprod Dev 66: 24-31, 2003.
17. Minas V, Jeschke U, Kalantaridou SN, Richter DU, Reimer T, Mylonas I, Friese K and Makrigiannakis A: Abortion is associated with increased expression of FasL in decidual leukocytes and apoptosis of extravillous trophoblasts: A role for $\mathrm{CRH}$ and urocortin. Mol Hum Reprod 13: 663-673, 2007.

18. Kiener PA, Davis PM, Rankin BM, Klebanoff SJ, Ledbetter JA, Starling GC and Liles WC: Human monocytic cells contain high levels of intracellular Fas ligand: Rapid release following cellular activation. J Immunol 159: 1594-1598, 1997.

19. Borges VM, Falcão H, Leite-Júnior JH, Alvim L, Teixeira GP, Russo M, Nóbrega AF, Lopes MF, Rocco PM, Davidson WF, et al: Fas ligand triggers pulmonary silicosis. J Exp Med 194: 155-164, 2001.

20. Dace DS, Khan AA, Stark JL, Kelly J, Cross AH and Apte RS: Interleukin-10 overexpression promotes Fas-ligand-dependent chronic macrophage-mediated demyelinating polyneuropathy. PLoS One 4: e7121, 2009.

21. Maugey-Laulom B, Commenges-Ducos M, Jullien V, Papaxanthos-Roche A, Scotet V and Commenges D: Endometrial vascularity and ongoing pregnancy after IVF. Eur J Obstet Gynecol Reprod Biol 104: 137-143, 2002.

22. Ding JL, Diao LH, Yin TL, Huang CY, Yin B, Chen C, Zhang Y, Li J, Cheng YX, Zeng Y and Yang J: Aberrant expressions of endometrial Id3 and CTLA-4 are associated with unexplained repeated implantation failure and recurrent miscarriage. Am J Reprod Immunol 78: 78, 2017.

23. Guirelli PM, Angeloni MB, Barbosa BF, Gomes AO, Castro AS, Franco PS, Silva RJ, Oliveira JG, Martins-Filho OA, Mineo JR, et al: Trophoblast-macrophage crosstalk on human extravillous under Toxoplasma gondii infection. Placenta 36: 1106-1114, 2015.

24. Nagamatsu T and Schust DJ: The immunomodulatory roles of macrophages at the maternal-fetal interface. Reprod Sci 17: 209-218, 2010.

25. Hamilton S, Oomomian Y, Stephen G, Shynlova O, Tower CL, Garrod A, Lye SJ and Jones RL: Macrophages infiltrate the human and rat decidua during term and preterm labor: Evidence that decidual inflammation precedes labor. Biol Reprod 86: 39, 2012.

26. Co EC, Gormley M, Kapidzic M, Rosen DB, Scott MA, Stolp HA, McMaster M, Lanier LL, Bárcena A and Fisher SJ: Maternal decidual macrophages inhibit NK cell killing of invasive cytotrophoblasts during human pregnancy. Biol Reprod 88: 155, 2013.

27. Shynlova O, Nedd-Roderique T, Li Y, Dorogin A and Lye SJ: Myometrial immune cells contribute to term parturition, preterm labour and post-partum involution in mice. J Cell Mol Med 17: 90-102, 2013.

28. Mor G and Abrahams VM: Potential role of macrophages as immunoregulators of pregnancy. Reprod Biol Endocrinol 1: 119, 2003.

29. Hemberger M, Hughes M and Cross JC: Trophoblast stem cells differentiate in vitro into invasive trophoblast giant cells. Dev Biol 271: 362-371, 2004.

30. Huppertz B, Kadyrov M and Kingdom JC: Apoptosis and its role in the trophoblast. Am J Obstet Gynecol 195: 29-39, 2006.

31. Straszewski-Chavez SL, Abrahams VM and Mor G: The role of apoptosis in the regulation of trophoblast survival and differentiation during pregnancy. Endocr Rev 26: 877-897, 2005.

32. Cinar O, Kara F and Can A: Potential role of decidual apoptosis in the pathogenesis of miscarriages. Gynecol Endocrinol 28: 382-385, 2012 .

33. Pang W, Zhang Y, Zhao N, Darwiche SS, Fu X and Xiang W: Low expression of Mfn2 is associated with mitochondrial damage and apoptosis in the placental villi of early unexplained miscarriage. Placenta 34: 613-618, 2013.

34. Lv X, Cai Z and Li S: Increased apoptosis rate of human decidual cells and cytotrophoblasts in patients with recurrent spontaneous abortion as a result of abnormal expression of CDKN1A and Bax. Exp Ther Med 12: 2865-2868, 2016.

35. Aschkenazi S, Straszewski S, Verwer KM, Foellmer H, Rutherford T and Mor G: Differential regulation and function of the Fas/Fas ligand system in human trophoblast cells. Biol Reprod 66: 1853-1861, 2002.

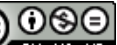

This work is licensed under a Creative Commons Attribution-NonCommercial-NoDerivatives 4.0 International (CC BY-NC-ND 4.0) License. 